\title{
Soil depth alters the consequences of species diversity for productivity in an experimental karst herbaceous community
}

\section{Yuan Liu ( $\sim$ liuyuan20100901@163.com )}

Key Laboratory of Eco-environments in Three Grorge Reservoir Region https://orcid.org/0000-00015409-8064

\section{Xuli Ren}

Key Laboratory of Eco-environments in Three Grorge Reservoir Region

\section{Qixiao Zhang}

Key Laboratory of Eco-environments in Three Grorge Reservoir Region

\section{Qiaoyu Li}

Key Laboratory of Eco-environments in Three Grorge Reservoir Region

\section{Chunyan She}

Key Laboratory of Eco-environments in Three Grorge Reservoir Region

\section{Haiyan Song}

Key Laboratory of Eco-environments in Three Grorge Reservoir Region

Jinchun Liu

Key Laboratory of Eco-environments in Three Grorge Reservoir Region

Jianping Tao

Southwest University

\section{Research Article}

Keywords: complementarity effect, karst herbaceous community productivity, selection effect, soil depth, species diversity

Posted Date: June 2nd, 2021

DOl: https://doi.org/10.21203/rs.3.rs-192673/v1

License: (c) (i) This work is licensed under a Creative Commons Attribution 4.0 International License.

Read Full License 
1 Soil depth alters the consequences of species diversity for productivity in an experimental karst Zuo who helped guide data analysis.

\section{herbaceous community} Jianping $\mathrm{Tao}^{2 *}$ 2

*Corresponding author: Jianping Tao

\# equal contribution

16

Acknowledgments

Yuan Liu ${ }^{1 \#}$, Xuli Ren ${ }^{1 \#, ~ Q i x i a o ~ Z h a n g ~}{ }^{1 \#, ~ Q i a o y u ~} \mathrm{Li}^{1}$, Chunyan She ${ }^{1}$, Haiyan Song ${ }^{1}$, Jinchun Liu ${ }^{1}$,

${ }^{1}$ Key Laboratory of Eco-environments in Three Gorges Reservoir Region, Chongqing Key Laboratory of Plant Ecology and Resources Research in Three Gorges Reservoir Region, School of Life Sciences, Southwest University, Chongqing 400715, China

$10 \quad{ }^{2}$ Chongqing Jinfo Mountain Field Scientific Observation and Research Station for Karst Ecosystem (Ministry of Education), Southwest University, Chongqing 400715, China

4 E-mail: taojianping@163.com; Tel.: +86-023-68252246; Fax: +86-023-68254533

8 This work was funded by National Key R\&D Program of China (2016YFC0502304). We thank

9 Yunrong Xiang, Wenchao Ma, and Miao Chen who helped with experimental soil collection, and Juan 21 


\section{Abstract}

Aims The mechanism by which species diversity drives productivity in different ecosystems is controversial, possibly due to the confounding effects of key environmental variables. Karst ecosystems are fragile and are at great risk of species loss. In these ecosystems, soil depth is a key driver of community diversity and productivity. However, the influence of soil depth on the relationship between species diversity and productivity in karst ecosystems remains unclear.

Methods We established artificial karst herbaceous communities with different soil depths and species richness levels and determined how two biodiversity effects - complementarity effect (effect of positive interactions among species) and selection effect (effect due to dominance of productive species) contributed to productivity.

Results Soil depth, species diversity, and different species combinations were significant predictors of productivity. Species diversity significantly positively affected productivity at all three soil depths, with the effect size of species diversity being the greatest in medium-depth soil. Net diversity effects were greater than 0 in all multi-species communities, indicating that complementarity and selection effects both positively influenced productivity. However, complementarity effect had a greater contribution to productivity than selection effect in all multi-species communities. Furthermore, the contribution of complementarity effect increased with increasing soil depth, while that of selection effect decreased.

Conclusions Soil depth influences the relationship between species diversity and productivity in karst herbaceous communities. Furthermore, complementarity effect is the major mechanism by which diversity increases community productivity, particularly in shallow soil. Therefore, environmental variables should be seriously considered when studying the relationship between species diversity and function in other ecosystems. 
Keywords: complementarity effect; karst herbaceous community productivity; selection effect; soil depth; species diversity

\section{Introduction}

Recent ecological research has often revolved around the controversy of the impact of species diversity on ecosystem functions (Loreau et al. 2001). Productivity is an important manifestation of ecosystem function (Chen and Qian 1997); therefore, the effect of species diversity on productivity has been extensively investigated. However, many previous studies have demonstrated that the relationship between species diversity and productivity varies among different natural communities, with studies finding positive, negative, unimodal, and no correlations (Redmann 1975; Zobel and Liira 1997; Yang et al. 2002; Hooper et al. 2005; Ruiz-Benito et al. 2014; Morandi et al. 2020). and the main mechanisms can be divided into two categories: complementarity effects and selection effects (Hector 1999; Gillman and Wright 2006; Forrester 2014). The former suggests that plant communities consisting of multiple species, which have different resource requirements and utilization patterns, have a higher overall ability to utilize limited resources, thus having greater productivity. In contrast, the latter, also named sampling effects, suggests that communities assembled with high-

61 diversity plant mixtures have a higher chance of containing and becoming dominated by the species that 62 achieves the highest productivity when grown alone, thus providing increasingly integrated productivity 63 of the community (Hector et al. 1999, Tilman 1999a, Tilman 1999b, Van der Putten et al. 2000, Liu 2019). 64 A number of studies have reported that complementarity and selection effects may operate in combination 
rather than separately (Loreau et al. 2002, Dai 2007). However, there is still a significant research gap in understanding the relationship between species diversity and productivity and its mechanism in karst plant communities. Recently, the species diversity of karst regions have been threatened by human activities, especially in a socio-economic context where the demand for resources is growing. Hence, it is increasingly imperative to determine the effect of species diversity on productivity in karst regions.

It has been reported that abiotic factors may affect the impact of species diversity on productivity (Bärlocher and Corkum 2003, Zhang and Zhang 2003). For example, Tilman (1995) found that community productivity was negatively related with species diversity during normal rainfall years, but positively related with species diversity during drought years in artificial grassland simulation experiments. Reich et al. (2001) indicated that increasing the $\mathrm{CO}_{2}$ concentration and content of nitrogen fertilizer significantly enhanced the positive effect of species diversity on productivity in grassland diversity experiments. Wu et al. (2018) conducted research in widely distributed secondary forests of subtropical regions, providing evidence that species richness and productivity showed a significant linear positive correlation under steep slopes but were uncorrelated under shallow slopes. Moreover, various other abiotic factors can affect the degree to which species diversity impacts the complementarity and selection effects and, therefore, community productivity (Fridley 2002, Cahill et al. 2010).

Karst is formed by chemical (dissolution of bedrock, such as limestone, dolomite, and gypsum) and physical processes (water erosion and disaggregation), and occupies more than $10 \%$ of the terrestrial surface (Legrand 1973). Karst landscapes are characterized by patchy soil and bare rock due to slow rates of bedrock weathering, and it takes about 300-800 years to create $1 \mathrm{~cm}$ of residual soil (Zhu 1997, Nie et al. 2011, Liu et al. 2018). In addition, the rate of soil formation is low and the permeability is high due to the high porosity of the underlying bedrock (Fu et al. 2016, Dai et al. 2017). Therefore, poor soil 
resources are the key factor limiting community species diversity and productivity in karst ecosystems.

Previous studies have found that soil depth can impact species diversity and community productivity in karst regions (Liu et al. 2020). However, how soil depth influences the mechanisms by which plant diversity affects community productivity in karst regions is still unknown. Therefore, we established artificial karst herbaceous communities with different soil depths and species richness levels, calculated the net biodiversity effect on productivity, and then partitioned this effect into the complementarity effect and selection effect. The main objectives were to examine: 1) the effects of soil depth, species diversity, and different species combinations on karst herbaceous community productivity; 2) the relationship between species diversity and productivity and the extent to which this relationship is affected by karst soil depth; 3) the contribution of the complementarity effect and selection effect to productivity in karst ecosystems with different soil depths.

\section{Materials and Methods}

\section{Experimental materials}

In our experiment, four typical karst plants, Bidens pilosa L., Xanthium sibiricum Patrin ex Widder., Setaria viridis (L.) Beauv, and Arthraxon hispidus (Thunb.) were selected as study plants to construct experimental herbaceous communities with different species diversity levels and three soil depths. The species are common in the karst plant communities of southwestern China, and all have traits that benefit the construction of artificial herbaceous communities, such as sufficient seeds and high emergence rates. The plant seeds and soil were collected from Zhongliangshan Haishi Park in Chongqing, a typical karst region in southwestern China. The experimental soil was a limestone soil (for initial soil chemistry, see Table 1) 


\section{Experimental design}

According to previous studies, soil depths of less than $30 \mathrm{~cm}$ are common, and the mean minimum soil depth is approximately $3.1 \mathrm{~cm}$ on the karst slopes of southwestern China (Yang et al. 2014, Zhang et al. 2018, Liu et al. 2019). Therefore, we designed a random block experiment with soil depths of $5 \mathrm{~cm}$ (shallow), $15 \mathrm{~cm}$ (medium), and $30 \mathrm{~cm}$ (deep) in our experiment. The three soil depths are appropriate for the rooting depths of the herbaceous plants used in the experiment (Li et al. 2017). Four levels of species richness were established by sowing seeds, ranging from monocultures to higher diversity assemblages. Each level of species richness contained different species combinations to investigate the effects of species combinations. In each level of species richness, the total quantity and density of seeds sown was kept constant, but the number of seeds of each species varied (Table 2). To prevent random interference, all treatments were replicated three times following a randomized complete block design. In total, 99 artificial herbaceous communities were established (11 community compositions $\times 3$ soil depths $\times 3$ replicates) .

The original test containers were plastic boxes with dimensions of $54 \mathrm{~cm} \times 38 \mathrm{~cm} \times 41 \mathrm{~cm}$ (length $\times$ width $\times$ height). The plastic boxes were cut to a height of $5 \mathrm{~cm}$ (shallow soil treatment), $15 \mathrm{~cm}$ (medium soil treatment), or $30 \mathrm{~cm}$ (deep soil treatment). The bases of the plastic boxes were pierced with 28 holes and covered with permeable geotextile to restrict root growth while ensuring water drainage. The containers were then filled with soil and placed in the Experimental Ecology Garden at Southwest University, Beibei, Chongqing, China $\left(106^{\circ} 24^{\prime} \mathrm{E}, 29^{\circ} 49^{\prime} \mathrm{N}\right)$. According to the experimental design, seeds were sown randomly over the test containers and then covered with a thin layer of soil on May 10 , 2018. When all experimental herbaceous communities were established in mid-June, we investigated the species composition and number of each herbaceous community, and subsequently artificially corrected 
the number of each species in the communities to conform to the experimental design.

\section{Growth measurements}

The experiment was conducted from mid-May to mid-October 2018, and all containers were watered daily with a manual sprinkler during the experimental period. On 5 October, we recorded the number of each component species in the containers. The harvest method was used to determine the fresh and dry weights of the species in the containers. All species harvested from containers were taken back to the laboratory and cleaned with water gently, then divided into aboveground and belowground tissue.

The tissues were oven dried at $80{ }^{\circ} \mathrm{C}$ to a constant mass and weighed to obtain aboveground and belowground biomass. Community productivity was measured as total dry aboveground and belowground biomass harvested in early October.

\section{Separation of species diversity effects}

According to the dichotomy of Loreau and Hector (2001), the increase in productivity (net biodiversity effects) in a multi-species community can be decomposed into the complementarity effect and the selection effect. The specific formula is:

$$
\begin{aligned}
& \Delta Y=Y_{O}-Y_{E}=\sum_{i} R Y_{O_{i}} M_{i}-\sum_{i} R Y_{E_{i}} M_{i}=\sum_{i} \Delta R Y_{i} M_{i} \\
& =N \overline{\Delta R Y M}+N \operatorname{cov}(\Delta R Y, M),
\end{aligned}
$$

where $\Delta Y$ is the net biodiversity diversity effect and is measured by the difference between the observed yield of a mixture and its expected yield under the null hypothesis that there is no selection effect or complementarity effect; $Y_{O}$ is the total observed yield of the mixture, which is the sum of the observed yield of component species in the mixture; $Y_{E}$ is the total expected yield of the mixture, which is the sum of the expected yield of component species in the mixture; $R Y_{O_{i}}=Y_{O_{i}} / M_{i}$ represents the observed relative yield of species $i$ in the mixture; $Y_{O_{i}}$ is the observed yield of species $i$ in the mixture; $M i$ is the 
yield of species $i$ in the monoculture; $R Y_{E_{i}}$ is the expected relative yield of species $i$ in the mixture, which is simply its proportion seeded; $\Delta R Y$ is the deviation from the expected relative yield of species $i$ in the mixture; $N$ is the number of species in the mixture; $N \overline{\Delta R Y M}$ measures the complementarity effect; and $N \operatorname{cov}(\Delta R Y, M)$ measures the selection effect.

\section{Statistical Analysis}

Normal Q-Q charts and Kolmogorov-Smirnov tests were used to test the normality of productivity (referred to as the total aboveground and belowground biomass in this experiment) for all experimental herbaceous communities. Community productivity conformed to a normal distribution (Supplementary material Appendix 1 Fig. A1). Then, a mixed linear model was constructed to analyze the effects of soil depth, species diversity, and their interaction on the productivity and average height of communities, where soil depth and species diversity were both fixed effects, and species combination and abundance were random effects. The fitness of the model was evaluated using $R_{c}^{2}$ (the proportion of variance explained by the full model) and $R_{m}^{2}$ (the proportion of variance explained by only the fixed effects) (Nakagawa and Schielzeth 2013). The mixed linear model was performed using R 3.5.3 (R Core Team 2019), with the "lmerTest" (Kuznetsova et al. 2015), "lme4" (Bates et al. 2019), and "Sjstats" packages (Lüdecke 2020).

Regression analysis was performed to determine the quantitative relationship between species diversity and community productivity among different soil depths. The multi-species effect, which represents the consequences of species diversity for herbaceous community productivity among different soil depths, can be calculated by the natural logarithm of the ratio of multispecies polyculture productivity to monoculture productivity (Hedges et al. 1999). The equation is as follows:

$$
\operatorname{Ln} R=\operatorname{Ln}\left(\frac{X_{t}}{X_{c}}\right)=\operatorname{Ln} X_{t}-\operatorname{Ln} X_{c}
$$


174

where $\operatorname{Ln} R$ represents the degree of influence, and $\operatorname{Ln} X_{t}$ and $\operatorname{Ln} X_{c}$ are the productivity of a multispecies polyculture and monoculture, respectively.

Two-way ANOVA was performed to analyze how different soil depths and species diversity affect multi-species community diversity, complementarity, and selection effects. Duncan's multiple range test was used to determine significant differences among treatments, with significance set at the $5 \%$ probability level. Statistical analyses were conducted using Microsoft Excel 2010 and SPSS 22.0 (IBM SPSS Statistics, Armonk, NY, USA), and the figures were plotted using Origin 8.5 (Origin, Northampton, MA, USA).

\section{Results}

The fixed effects, including soil depth, species diversity, and their interaction, all imposed a significant influence on karst herbaceous community productivity $(p<0.05)$ (Table 3$)$. The plant community productivities of different species combinations in deep soil were significantly higher than those in shallow soil (Figure 1). Additionally, the random effects and species combination also significantly affected community productivity, but community abundance had no significant effect on community productivity (Table 3). Productivity differed significantly among monoculture communities, with the monoculture of Xanthium sibiricum being the highest while the monoculture of Arthraxon hispidus was the lowest (Figure 1). It is worth mentioning that the highest productivity among the multispecies communities occurred when species diversity was greatest, referring to the mixture of $X$. sibiricum + S. viridis + A. hispidus + B. pilosa $($ Figure 1).

Herbaceous community productivity increased linearly with increasing species diversity at different soil depths (shallow soil: $\mathrm{R}^{2}=0.37, p<0.01$; medium soil: $\mathrm{R}^{2}=0.39, p<0.01$; deep soil: $\mathrm{R}^{2}=0.38, p<$ 
0.01). The community productivity in the mixture with the most species was significantly greater than that of the others, and the average productivity was $2.17,2.50$, and 2.32 times the average productivity of monocultures, in shallow, medium, and deep soil, respectively (Figure 2). Species diversity exerted a positive influence on community productivity in all communities at different soil depths, but the effect size of species diversity being the greatest in medium-depth soil (Figure 3).

The net biodiversity effects (species diversity $\geq 2$ ) on productivity were always greater than 0 in all multi-species communities: the complementarity effect ranged from 3.26 to 17.22 and therefore had a positive impact on all multi-species productivity; the selection effects ranged from -4.36 to 17.76 , indicating that it had a positive effect on productivity in $89 \%$ of multi-species communities (Figure 4 ). As soil depth and species diversity increased, the net biodiversity effect, complementarity effect, and selection effect all significantly increased in multi-species communities (Figure 4). Among different soil depths and species diversities, the impact of the complementarity effect was greater than that of the selection effect. As soil depth increased, the proportion of net biodiversity effects that were complementarity effects decreased, while the proportion that were selection effects increased (Figure 5).

\section{Discussion}

\section{Effects of soil depth and species diversity on karst herbaceous community productivity}

Biotic and abiotic conditions are both important factors affecting community productivity. The mixed linear model revealed that soil depth, species diversity, and their interaction all had a critical effect of community productivity (Table 3 and Figure 1). The soil fertility hypothesis states that the more soil nutrient resources, the higher the community productivity (Wright et al. 2011, Quesada et al. 2012). Soil depth is a key factor in determining nutrient resources, as deeper soil contains a higher availability of 
soil resources (Wu et al. 2018). The yellow limestone soil from the karst area in this experiment had low soil fertility (Zeng 2019), with increasing soil depth not only increasing living space of plant, but also greatly increasing overall soil nutrients (Belcher et al. 1995). Therefore, the productivity in deep soil significantly exceeded that in shallow soil, regardless of the species richness of the community. Consistent with a large number of former studies, our experiment indicated that species diversity had a positive effect on plant community productivity (Tilman et al. 2001, Potter and Woodall 2014, Liang et al. 2016). Moreover, we also observed that the relationship between species diversity and productivity was linear at the three soil depths in our experiment. This may be because communities with higher diversities contain a range of species possessing different traits (such as root length, root density, crown height, photosynthesis rate, growth rate, etc.), which can therefore exploit a range of resources ensuring efficient resource exploitation. Thus, a higher diversity leads to greater community productivity (Hooper 1998).

The species combinations (or species characteristics) also had a considerable impact on the productivity of the experimental herbaceous communities (Table 3). The same species can have different interactions with others in communities with different species combinations because of different species had different function traits (Jiang and Zhang 2006). This could explain why there were large variations in productivity among communities with the same diversity level but different species combinations (Figure 1). There were no significant differences in abundance, owing to the uniform seed amount and daily management in all experimental herbaceous communities. Consequently, there was no effect of community abundance on productivity and average height in our experiment.

\section{Soil depth influenced the magnitude of the effect of species diversity on community productivity} Across all three soil depths, species diversity had a positive impact on plant community productivity. 
To some extent, high species diversity likely alleviated the negative effect of shallow soil on plant community productivity in the karst region. Numerous studies have indicated that the lower the availability of soil nutrients, the stronger the impact of species diversity on plant community productivity (Pretzsch et al. 2013, Ali and Yan 2017). In this study, we also found that the impact of species diversity on community productivity varied with soil depth (Figures $1 \mathrm{~b}, 2$, and 3 ). This could be because deeper soil increased soil nutrients and living space of plant, directly increasing community productivity, but experimental herbaceous communities with fewer species in deep soil could not effectively improve the niche dimension, therefore species diversity in deep soil, where resources and space were more abundant than in medium-depth soil, showed weaker positive effects (Harpole and Tilman 2007, Dai et al. 2009). At the same time, the limited resource availability in shallow soil restricted the opportunities of species to exploit complementary resources, especially for the key species, leading to positive effects in shallow soil being lower than those in medium-depth soil.

\section{Soil depth influences the mechanisms by which species diversity affects karst herbaceous} community productivity

We found a positive complementarity effect in all multi-species communities and a positive selection effect in $89 \%$ of multi-species communities, indicating that the complementarity and selection effects were compatible and both positively influenced productivity to some extent. In multi-species communities dominated by the complementarity effect, the interactions between species contributed more to the ecosystem function, while for communities dominated by the selection effect, dominant species contributed more. In addition, complementarity and selection effects may lead to different ecological conditions during community succession (Huston 1997). Plant communities with a single dominant species are more easily affected by the selection effect. If habitats are altered to the detriment 
of dominant species (e.g., as a result of natural stress or human disturbance), the ecological function of the community may be damaged irreversibly because the dominant species might not be quickly replaced by another species. Conversely, if complementarity effects dominate, habitat changes that are negative for one dominant species have less of an effect because there are other dominant species with similar functions which can maintain community stability. Consistent with other short-term grassland diversity experiments, the complementarity effect contributed more to community productivity in our experimental herbaceous communities, indicating that this is the main mechanism by which species diversity affects community productivity in karst areas. Moreover, the ecosystem functions of the experimental communities were relatively stable even though they were subjected to environmental stress.

The contribution of the complementarity and selection effects to productivity can be affected by environmental factors. Several studies have suggested that complementarity effects play a more important role in low-productivity communities or harsh environments, where competition barely affects species interactions (Warren et al. 2009, Paquette and Messier 2011). This was consistent with our results.

274 Deep soil has enough nutrients and water for plant growth, which can decrease the spatial diversity of resource utilization, and therefore decrease the spatial function of complementarity effects (Abrams 1995,

276 Fridley 2001, He et al. 2013). This could explain why, with increasing soil depth, the contribution of the complementarity effect to the net biodiversity effect decreased, while the contribution of the selection effect increased.

\section{Conclusions}


herbaceous community productivity. Community productivity was significantly affected by species combinations under the same level of species diversity. Therefore, it may be feasible to enhance community productivity by protecting soil resources and species diversity in karst regions. Moreover, different plant species combinations need to be considered in the management of degraded karst ecosystems. Our study also demonstrates that the effect of species diversity on community productivity differs depending on soil depth, emphasizing the need to consider environmental factors when studying the relationship between species diversity and ecosystem function.

The complementarity and selection effects both positively affected community productivity, with the contribution of the complementarity effect being greater than that of the selection effect. As a result, the plant community was stable despite environmental stress. Considering complementary effect and selection effect can result in different ecology conditions, it is very critical to clarify their contribution to community productivity in a dynamic environment.

\section{Supplementary material: Appendix A.}

\section{Declarations of interest: none}

\section{References}

Abrams PA (1995) Monotonic or unimodal diversity-productivity gradients: what does competition theory predict. Ecology 76: 2019-2027. https://doi.org/10.2307/1941677

Ali A, Yan ER (2017) The forest strata-dependent relationship between biodiversity and aboveground biomass within a subtropical forest. Forest Ecol. Manag. 401: 125-134. https://doi.org/10.1016/j.foreco.2017.06.056

Bärlocher F, Corkum M (2003) Nutrient enrichment overwhelms diversity effects in leaf decomposition 
Bates D, Maechler M, Bolker B, Walker S, Christensen B, Singmann H, Dai B, et al. (2019) Lme4: linear mixed-effects models using "Eigen" and S4. R package version 1.1-21. https://CRAN.Rproject.org/package $=$ lme4.

Belcher JW, Keddy PA, Twolan-Strutt L (1995) Root and shoot competition intensity along a soil depth 
Fridley JD (2002) Resource availability dominates and alters the relationship between species diversity and ecosystem productivity in experimental plant communities. Oecologia 132: 271-277. https://doi.org/10.1007/s00442-002-0965-x

Fu TG, Chen HS, Wang KL (2016) Structure and water storage capacity of a small karst aquifer based on stream discharge in Southwest China. J. Hydrol. 534: 50-62. https://doi.org/ 10.1016/j.jhydrol.2015.12.042

Gillman LN, Wright SD (2006) The influence of productivity on the species richness of plants: a critical assessment. Ecology 87: 1234-1243. https://doi.org/10.1890/0012-9658(2006)87[1234:TIOPOT]2.0.CO;2

Harpole WS, Tilman D (2007) Grassland species loss resulting from reduced niche dimension. Nature 446: 791-793. https://doi.org/10.1038/nature05684

He Q, Bertness MD, Altieri AH (2013) Global shifts towards positive species interactions with increasing environmental stress. Ecol. Lett. 16: 695-706. https://doi.org/10.1111/ele.12080

Hector A, Schmid B, Beierkuhnlein C, Caldeira MC, Diemer M, Dimitrakopoulos PG, Finn JA (1999) Plant diversity and productivity experiments in European grasslands. Science 286: 1123-1127. https://doi.org/10.1126/science.286.5442.1123

Hedges LV, Gurevitch J, Curtis PS (1999) The meta-analysis of response ratios in experimental ecology. Ecology 80: 1150-1156. https://doi.org/10.1890/0012-9658(1999)080[1150:TMAORR]2.0.CO;2

Hooper DU (1998) The role of complementarity and competition in ecosystem responses to variation in plant diversity. Ecology 79: 704-719. https://doi.org/10.1890/0012-9658(1998)079[0704:tro cac]2.0.co;2 
Hooper DU. Chapin FS, Ewel JJ, Hector A, Inchausti P, Lawton JH, Lodge DM, et al. (2005) Effects of biodiversity on ecosystem functioning: a consensus of current knowledge. Ecol. Monogr. 75: 3-35. https://doi.org/10.1890/04-0922

Huston M (1997) Conservation and biodiversity. Trends Ecol. Evol. 12: 246. https://doi.org/ $10.1016 / \mathrm{s} 0169-5347(97) 86969-8$

Jiang XL, Zhang WG (2006) Separating sampling effect from complementary effect in the annual plant communities. Acta Ecol. Sin. 26: 1896-1902. (in Chinese) https://doi.org/10.3321/j.issn:10000933.2006.06.034

Kuznetsova, Brockhoff PB, Christensen RHB (2015) LerTest: tests in linear mixed effects models. R package version 3.1-1. https://CRAN.R-project.org/package=LmerTest.

Legrand HE (1973) Hydrological and ecological problems of karst regions: hydrological actions on limestone regions cause distinctive ecological problems. Science 179: 859-864. https://doi.org/10.1126/science.179.4076.859

Li Z, Liu JC, Zhao YJ, Song HY, Liang QH, Tao JP (2017) Adaption of two grasses to soil thickness variation under different water treatments in a karst region. Acta Ecol. Sin. 37: 298-306. https://doi.org/10.1016/j.chnaes.2017.09.001

Liang JJ, Crowther TW, Picard N, Wiser S, Zhou M, Alberti G, Schulze ED, McGuire AD, et al. (2016) Positive biodiversity-productivity relationship predominant in global forests. Science 354: aaf8957. https://doi.org/10.1126/science.aaf8957

Liu C (2019) Mechanism of impact of fine roots functional traits and species richness on fine root production in subtropical Forests. Central South University of Forestry \& Technology. (in Chinese)

Liu CC, Liu YG, Guo K, Qiao XG, Zhao HW, Wang SJ, Zhang L, et al. (2018) Effects of nitrogen, 

and community perspectives. Ecol. Eng. 117: 84-95. https://doi.org/10.1016/j.ecoleng.2018.04.008

Liu X, Zhang W, Wu M, Ye YY, Wang KL, Li DJ (2019) Changes in soil nitrogen stocks following vegetation restoration in a typical karst catchment. Land Degrad Dev. 30: 60-72. https://doi.org/ 10.1002/ldr.3204

Liu Y, Chen J, Zhang XJ, Li QY, Du Y, Liu JC, Tao JP (2020) Herbaceous community species 1589-8 
392 Nie YP, Chen HS, Wang KL, Tan W, Deng PY, Yang J (2011) Seasonal water use patterns of woody species growing on the continuous dolostone outcrops and nearby thin soils in subtropical China. Plant Soil 341: 399-412. https://doiorg/ 101007/s11104-010-0653-2

Paquette A, Messier C (2011) The effect of biodiversity on tree productivity: from temperate to boreal forests. Glob. Ecol. Biogeogr. 20: 170-180. https://doi.org/10.1111/j.1466-8238.2010.00592.x

Potter KM, Woodall CW (2014) Does biodiversity make a difference? relationships between species

Pretzsch H, Bielak K, Block J, Bruchwald A, Dieler J, Ehrhart HP, Kohnle U, et al. (2013) Productivity https://doi.org/10.1007/s10342-012-0673-y

Quesada CA, Phillips OL, Schwarz M, Czimczik CI, Baker T, Patino S, Fyllas NM, et al. (2012) Basinwide variations in Amazon forest structure and function are mediated by both soils and climate. Biogeosciences 9: 2203-2246. https://doi.org/10.5194/bg-9-2203-2012

R Core Team (2019) R: a language and environment for statistical computing. URL https://www.Rproject.org/. R Foundation for Statistical Computing, Vienna, Austria.

Redmann RE (1975) Production ecology of grassland plant communities in Western North Dakota. Ecol.

411 Reich PB, Knops J, Tilman D, Cralne J, Ellsworth D, Tjoelker M, Lee T, et al. (2001) Plant diversity 

https://doi.org/10.1038/35071062

Ruiz-Benito P, Gomez-Aparicio L, Paquette A, Messier C, Kattge J, Zavala MA (2014) Diversity increases carbon storage and tree productivity in Spanish forests. Glob. Ecol. Biogeogr. 23: 311322. https://doi.org/10.1111/geb.12126

Tilman D (1995) Biodiversity: population versus ecosystem stability. Ecology 77: 350-363. https://doi.org/10.2307/2265614

Tilman D (1999a) The ecological consequences of changes in biodiversity: a search for general principles. Ecology 80: 1455-1474. https://doi.org/10.2307/176540

Tilman D (1999b) Ecology: diversity and production in European grasslands. Science 286: 1099-1100. https://doi.org/10.1126/science.286.5442.1099

Tilman D, Reich PB, Knops J, Wedin D, Mielke T, Lehman C (2001) Diversity and productivity in a long-term grassland experiment. Science 294: 843-845. https://doi.org/10.1126/science.1060391 

species richness and biomass/productivity depend on environmental factors in secondary forests of Dinghai, Zhejiang Province. Biodivers. Sci. 26: 545-553. (in Chinese) https://doi.org/10.17520/biods.2017320

Yang LM, Zhou GS, Li JD (2002) Relationship between productivity and plant species diversity of grassland communities in Songnen plain of Northeast China. Acta Phytoecologica Sin. 26: 589-593. (in Chinese) https://doi.org/10.1006/jfls.2001.0409

Yang QY, Zhang FW, Jiang ZC, Li WJ, Zhang JB, Zeng FM, Li H (2014) Relationship between soil depth and terrain attributes in karst region in Southwest China. J. Soils Sediments 14: 1568-1576. https://doi.org/10.1007/s11368-014-0904-6

Zeng JM (2019) Response of spatial differentiation of soil properties to vegetation restoration in consequent/reverse slopes of karst trough Valley. Southwest University. (in Chinese)

Zhang QG, Zhang DY (2003) Biodiversity and ecosystem functioning: recent advances and trends. Biodivers. Sci. 11: 351-363. https://doi.org/10.1016/j.inoche.2012.12.010

Zhang XQ, Hu MC, Guo XY, Yang H, Zhang ZK, Zhang KL (2018) Effects of topographic factors on runoff and soil loss in Southwest China. CATENA 160: 394-402. https://doi.org/ 10.1016/j.catena.2017.10.013

Zhu SQ (1997) Ecological research on karst forest (II). Guizhou Science and Technology Press. (in Chinese)

Zobel K, Liira J (1997) A scale-independent approach to the richness vs biomass relationship in groundlayer plant communities. Oikos 80: 325-332. https://doi.org/ 10.2307/3546600 
Figures

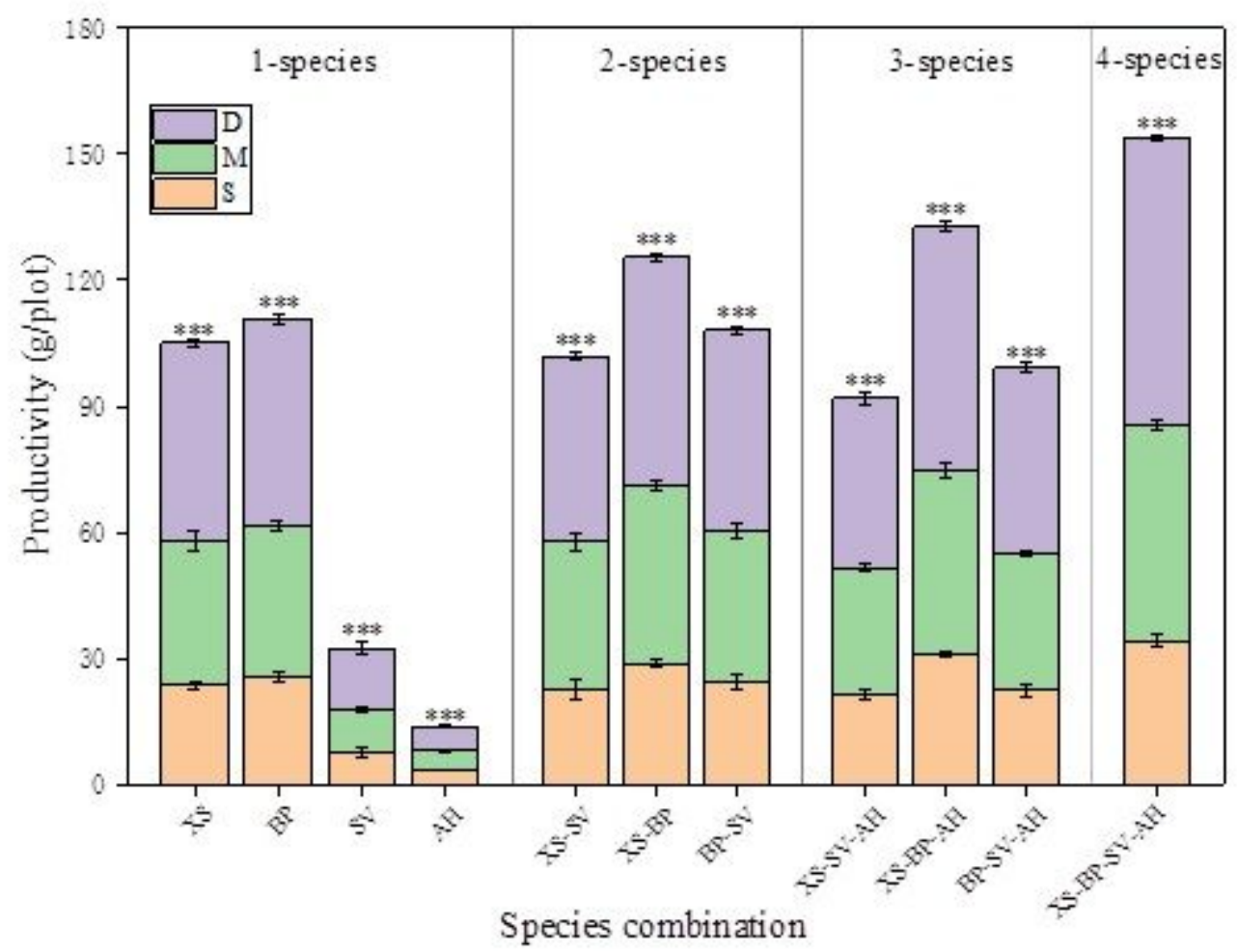

Figure 1

Plant community productivity in different soil depths for all plots with different species combinations. Data are mean \pm SE. S: shallow soil depth; M: medium soil depth; $D$ : deep soil depth. Asterisks indicate significant differences among the soil depths: ${ }^{*}, p<0.05$; ${ }^{\star *}, p<0.01$; ${ }^{\star \star *}, p<0.001$. BP, Bidens pilosa; XS, Xanthium sibiricum; SV, Setaria viridis; $\mathrm{AH}$, Arthraxon hispidus. 


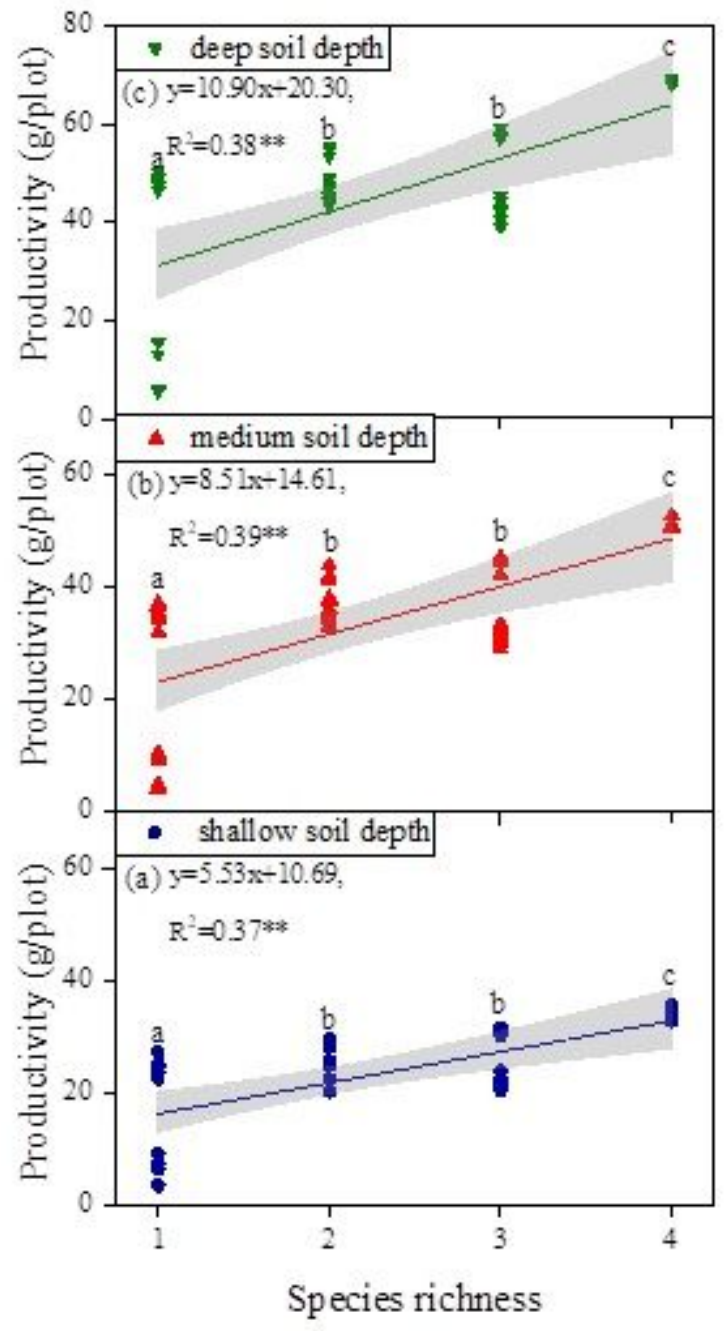

Figure 2

The relationship between plant species richness and community productivity in (a) shallow soil depth, (b) medium soil depth, and (c) deep soil depth. Statistical significance of the regression models is indicated by * at $p<0.05$ and ** at $p<0.01$. Different lowercase letters indicate significant differences among species diversity at $p<0.05$. Grey shading represents $95 \%$ credible intervals. 


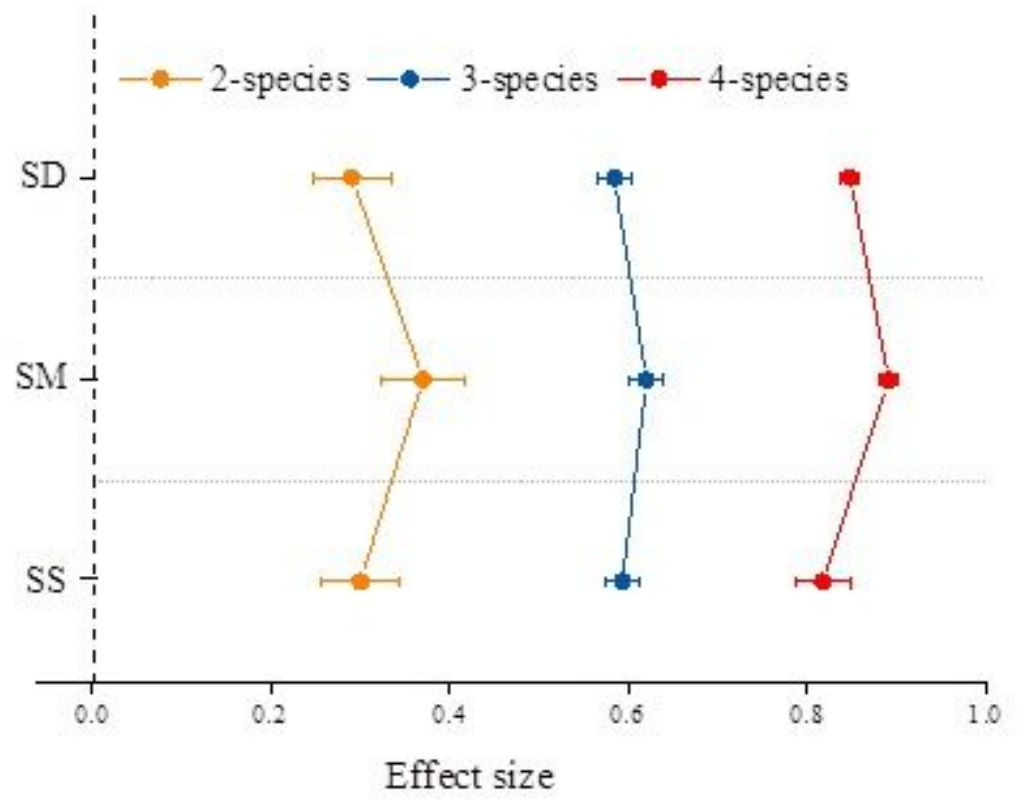

\section{Figure 3}

The effect size of species diversity on plant community productivity in different soil depths. Data are mean \pm SE. S: shallow soil depth; M: medium soil depth; D: deep soil depth. 

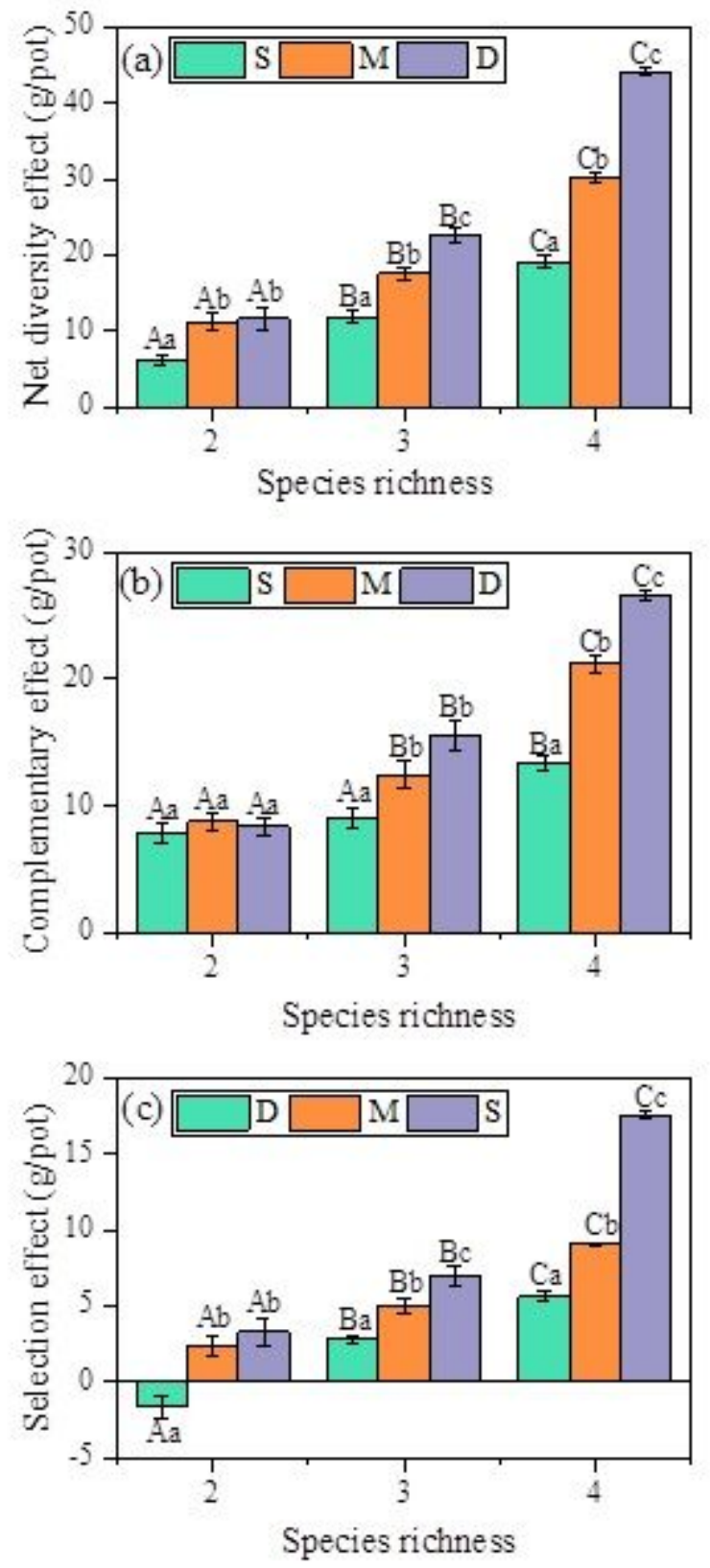

Figure 4

The net biodiversity effect (a), complementarity effect (b), and selection effect (c) of each species richness level in different soil depths. Data are mean \pm SE. S: shallow soil depth; M: medium soil depth; D: deep soil depth. Different capital letters indicate significant differences among species richness levels at $p<0.05$. Different lowercase letters indicate significant differences among soil depths at $p<0.05$. 


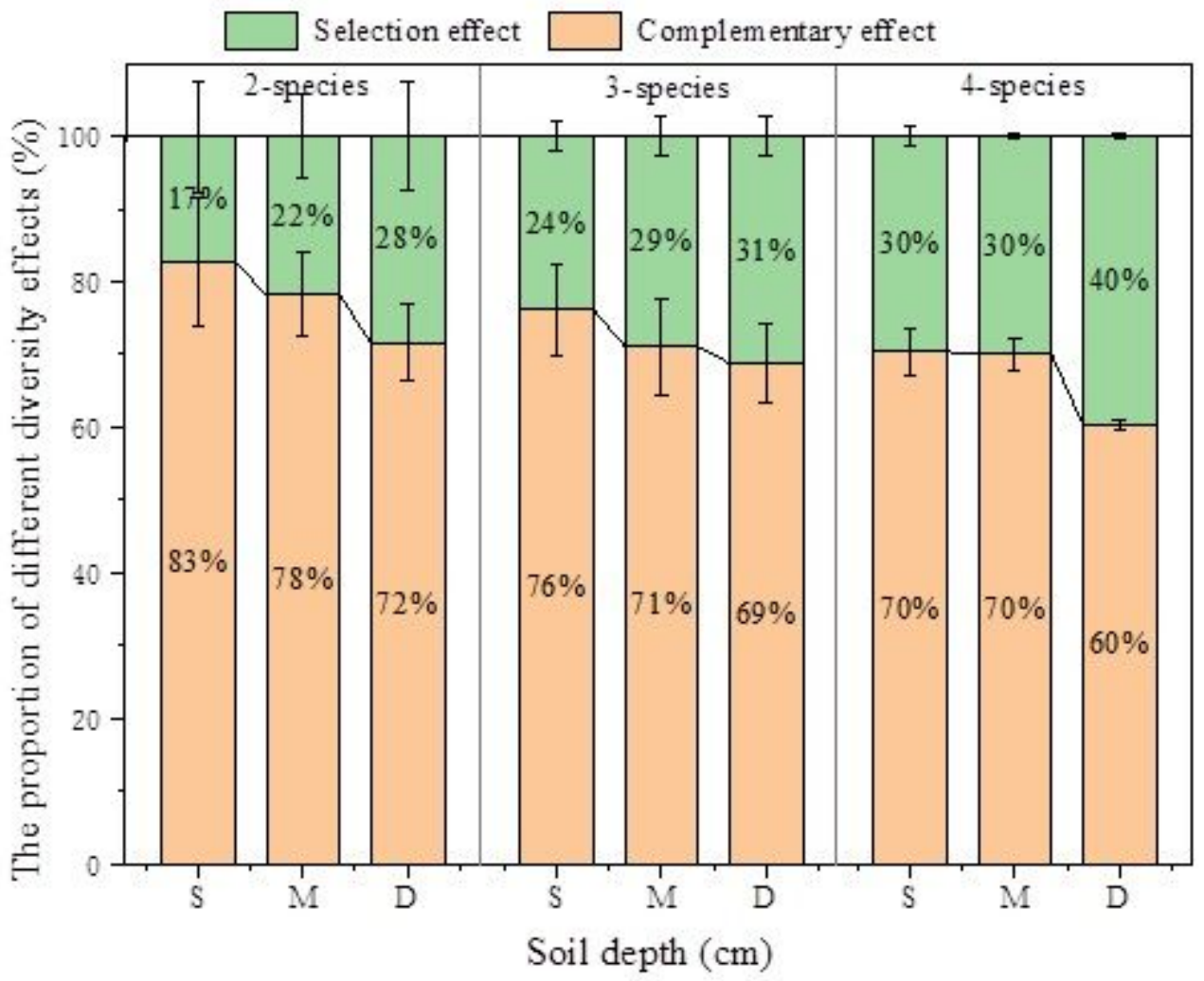

Figure 5

The contribution (\%) of the complementarity effect and selection effect to the net biodiversity effect for different species richness levels and soil depths. Data are mean \pm SE. S: shallow soil depth; M: medium soil depth; D: deep soil depth.

\section{Supplementary Files}

This is a list of supplementary files associated with this preprint. Click to download.

- Table.pdf

- AppendixA.docx 